\title{
THE EFFICACY OF ARTHROCENTESIS ON RESTORING MANDIBULAR FUNCTION IN UNILATERAL SUBCONDYLAR FRACTURE FOLLOWING MAXILLOMANDIBULAR FIXATION (A CLINICO-RADIOGRAPHIC STUDY)
}

\author{
Sinbel A ${ }^{1} B D S$, Shaaban $A^{2} P h D$, Shokry $\mathrm{M}^{3} P h D$.
}

\begin{abstract}
:
Introduction: Arthrocentesis can be used as a treatment modality in cases of subcondylar fracture treated with maxillomandibular fixation to restore the normal mandibular movements.

Objective: Was to evaluate the efficacy of arthrocentesis on restoring mandibular function in unilateral subcondylar fracture following maxillomandibular fixation.

Materials and Methods: This study was conducted on twenty patients suffering from unilateral subcondylar fracture with/without contra-lateral parasymphyseal or body fracture where open reduction with plate fixation for the contralateral fracture and closed reduction with 2 weeks MMF for the subcondylar fracture was done. The patients were divided into two groups: Group I (study group) in which ten patients were treated with active mobilization and arthrocentesis following MMF removal, and Group II (control group) in which ten patients were treated with only active mobilization following MMF removal. Groups I \& II were also subdivided into A \& B each involved five patients with isolated subcondylar fracture and five patients with contralateral parasymphyseal or body fracture in addition.

Results: There was a statistically significant decrease in pain and edema and a statistically significant increase in the mouth opening, lateral excursive and protrusive movements in addition to the bite force through-out all follow up periods in the study group especially after the application of arthrocentesis in comparison to the control group.

Conclusions: Arthrocentesis (TMJ lavage) was an effective procedure for washing out inflammatory mediators present within the TMJ following the exposure to trauma and showed a significant improvement in mandibular movements immediately after performing it. This helped in improving the quality of the patients' life enabling them to practice their usual activities and return back to normal life starting from the second week
\end{abstract} postoperatively i.e patients rehabilitation occurred in a short period.

Key Words: Arthrocentesis, subcondylar fracture, maxillomandibular fixation.

1- B.D.S 2008, Faculty of Dentistry, Alexandria University

2-Professor of Oral \& Maxillofacial Surgery, Faculty of Dentistry, Alexandria University

3-Assistant Professor of Oral and Maxillofacial Surgery, Faculty of Dentistry, Beirut Arab University

\section{INTRODUCTION}

The mandible is the second most commonly fractured part of the maxillofacial skeleton because of its position and prominence $(1,2)$. Among which mandibular condylar fractures account for $17.5-50 \%$ of all mandibular fractures (3).

Injury to the maxillofacial skeleton may be caused by a variety of mechanisms and causes which includes motor vehicle accident, interpersonal violence, work related incidents, sporting accidents and falls (4). The type of fracture produced following an injury depends on the age of the patient and is affected by the direction and magnitude of the force. For example; a blow directed horizontally to the mandibular body, such as that provided by a fist, results in a fracture of the ipsilateral mandibular body and the contralateral condyle (4).

The proper management of the fractured mandibular condyle is one of the most controversial topics in maxillofacial trauma (4). Restoration of mandibular function, in particular, as part of the stomatognathic system must include the ability to masticate properly, to speak normally, and to allow for articular movements as ample as before the trauma (5).

Treatment is generally divided into conservative or nonsurgical and surgical approaches (4). Open reduction with internal fixation (ORIF) is indicated in case of bilateral condylar fractures, limitation of function, inability to maintain occlusion or where closed reduction will result in a high degree of failure but the risk of avascular necrosis and osseous or fibrous ankylosis is high in patients when treated with ORIF which make conservative treatment more preferred $(5,6)$. Conservative treatment requires varying periods of maxillomandibular fixation (MMF) followed by aggressive physiotherapy (7).

This period currently ranges from 7 to 21 days which may be increased or decreased based on the age of the patient, level of fracture, degree of displacement and the presence of additional fractures (4).

The period of immobilization is controversial and must be long enough to allow initial union of the fracture segments but short enough to prevent complications such as 
muscle atrophy and joint ankylosis. It is better that maxillomandibular fixation be discontinued in all patients at approximately 10 to 14 days. In case of the presence of contralateral body, or parasymphyseal fractures open reduction and fixation of them will allow early mobilization of an associated condylar fracture which allow for the early release of MMF without compromising the healing of these other fractures (5).

The effect of MMF on the masticatory system must be taken in consideration together with the negative muscloskeletal changes that prolonged MMF may cause despite the advantages of conservative treatment (8). These changes include atrophy of the muscles of mastication, thinning of the condylar cartilage of the temporomandibular joint (TMJ), and decreased range of mandibular opening (9-11). Some of these changes are reversible to varying degrees, depending on when function is restored via intensive physiotherapy. It has also been shown through several studies that arthrocentesis of the upper compartment of the TMJ (a method of flushing out TMJ) may be highly effective method to restore manual mouth opening and functioning (12).

Since the presence of the pro-inflammatory cytokines interleukin (IL)-6 is detected in patients with subcondylar fractures (13) because these inflammatory mediators initiate pain and limit the normal mandibular movements arthrocentesis can be used as a treatment modality for subcondylar fractures where it wash away the inflammatory mediators, leading to quick recovery of jaw function $(6,14)$.

This study was performed to hypothesize whether arthrocentesis is efficient in restoring mandibular function in unilateral subcondylar fracture or not in comparison to active mobilization only following the removal of maxillomandibular fixation.

\section{MATERIALS AND METHODS}

This study was performed as a controlled randomized clinical trial and was performed on twenty patients suffering from unilateral subcondylar fracture with/without contralateral parasymphyseal or body fracture where open reduction with plate fixation for the contralateral fracture and closed reduction with 2 weeks MMF for the subcondylar fracture was done. The ethical clearance was obtained by the ethical committee before starting the study, the selected patients were informed about the nature of the study and informed consents were obtained. The patients were divided into two groups:

Group I (study group): Ten patients were treated with active mobilization and arthrocentesis following MMF removal. (Fig. 1a-c)

Group II (control group): Ten patients were treated with only active mobilization following MMF removal. I- Preoperative assessment and examination:

Every patient was assessed and evaluated by proper history taking, thorough clinical and radigraphical examination as follows:

A- History of the patient: The onset of the mandibular fracture should not exceed more than one week from the day of the trauma. The pre-operative data was collected and recorded in full details in an examination sheet including name, age, gender, occupation, address, onset, etiology of the fracture and present complain in addition to the past medical history.

B- Clinical examination: Both extraoral and intraoral examination were done through inspection and palpation to detect site of tenderness, step defects and bony in addition to examination of TMJ which was done by palpation over the condyle area through placing the little finger in the external auditory canal while the palm directed forward and the patient was instructed to attempt to move the mandible in all directions in order to detect any condylar movement impairment during opening and closing, dislocation of condylar head from the glenoid fossa and/or tenderness over the preauricular area.

C-Radiographic examination: Standard orthopantomogram (OPG) and reverse Towne's view were taken for all patients at the time of presentation. Other necessary radiographic examination was requested according to each case.

\section{II- Pre-operative preparation:}

For all patients, maximum interincisal mouth opening, lateral excursive and protrusive movement were measured preoperatively as a baseline by vernier-calibrated sliding calipers using the incisal edge of the maxillary central incisor and that of the mandibular central incisor as reference points (15).

The bite force was also measured preoperatively as a baseline using Pressure Indicating Film which is an easy tool that reveals the distribution and magnitude of the force between any two contacting, mating or impacting surfaces.

Clinical follow up was carried out to assess the previous measures at intervals of two, four, six and twelve weeks post operatively, removal of MMF was done within 2 weeks after which the group I (study group) received arthrocentesis while in the group II (control group) was instructed for active mobilization only.

The Procedure of superior joint space arthrocentesis was as follows (16-18): (Fig.1)

- The joint was palpated during mandibular movements to locate the condyle and the mandibular fossa.

- The pre-auricular region was cleaned with Betadine swab (Povidone-Iodine U.S.P. 10\% W/V. Manufactured by: the Nile Co. for pharmaceuticals and Chemical Industries Cairo - A.R.E. Licensed by Mundipharma AG - Basel Switzerland) and the area was isolated with sterile towels.

- A mark was made $1 \mathrm{~cm}$ in front of the tragus along with the lateral canthal-tragus line (canthotragal line) and $2 \mathrm{~mm}$ below the tragus.

- Block analgesia was done to the auriculotemporal nerve with Mepecaine-L (Each carpule is $1.8 \mathrm{ml}$. Each $\mathrm{ml}$ of Mepecaine-L contains: Mepevacaine $\mathrm{HCl}$ 3\%. Produced by: Alexandria Co. for pharmaceuticals, Alexandria, Egypt. www.alexcopharma.net).

- Shepherd arthrocentesis instrument $18 \mathrm{~g} \times 2.5$ " (Shepherd Arthrocentesis Instrument, 18gx2.5-ACE Surgical Supply) was inserted into the superior chamber 
according to the mark previously done

- About $50 \mathrm{cc}$ sterile normal saline solution was used for lavage of the superior joint space through the in part of the Shepherd arthrocentesis instrument.

- A free flow of the solution was collected in a kidney dish through the out part of the Shepherd arthrocentesis instrument.

- After removing the Shepherd arthrocentesis instrument, the jaw was gently manipulated in vertical, protrusive and lateral excursions.

- Hair or beard over the joint was shaved.
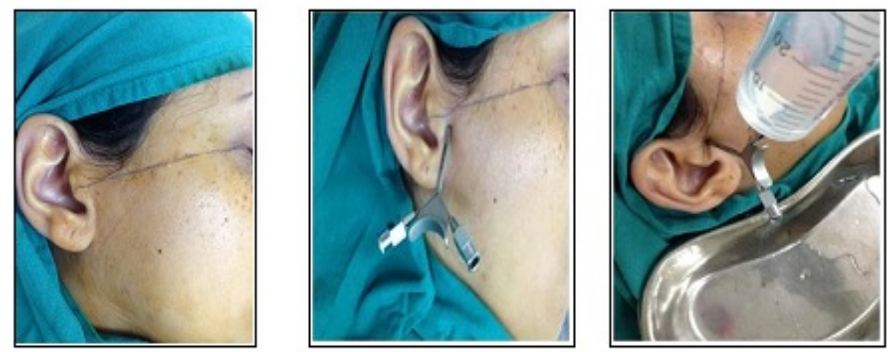

Fig. 1: Showing arthrocentesis procedure a) Landmarks for arthrocentesis, b) Insertion of shephered arthrocentesis instrument, c) Arthrocentesis using normal saline.

\section{III- Radiographic follow up:}

The patients were radiographically assessed immediately after the operation, six and twelve weeks postoperatively. It included orthopantomogram to assess the adequacy of reduction of the fractured segments and the fracture healing progression. OPG and Towne's view were required preoperatively to assess the results. (Fig. 2)
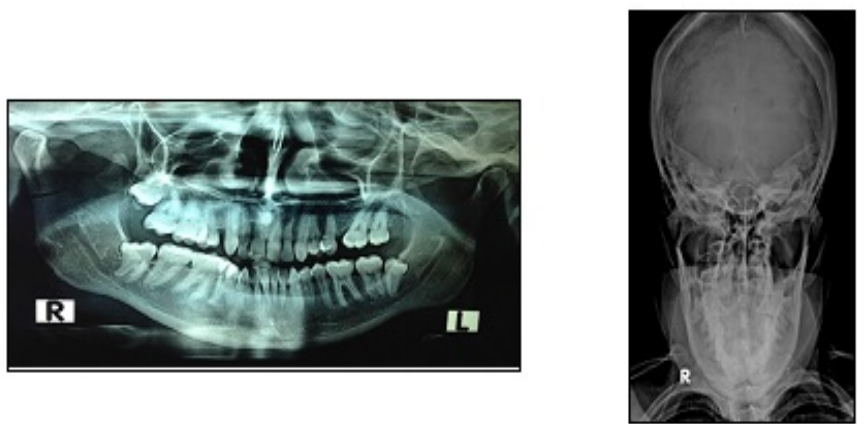

Fig. 2: Showing preoperative OPG and Towne's view showing isolated right subcondylar fracture.

Data were fed to the computer and analyzed using IBM SPSS software package version $20.0(19,20)$. Quantitative data were described using range (minimum and maximum), mean, standard deviation and median. Comparison between two independent samples was done using independent t-test, also paired t-test was used to analyze two paired data, comparison between different periods using ANOVA with repeated measures. Significance of the obtained results was judged at the $5 \%$ level.

\section{RESULTS}

The study was performed on twenty patients; seven males and thirteen females; with a ratio of 1:2. They were treated in the Oral and Maxillofacial Surgery Department, Faculty of Dentistry, Alexandria University. Patients' age ranged from 20 to 50 years old with a mean age of $30.45 \pm 9.638$.

The etiological factors of the fractures were $(45 \%)$ road traffic accidents (RTA), (30\%) interpersonal violence (IPV), and $(25 \%)$ fall.

\section{Clinical results:}

Every case was monitored at the intervals of two, four, six and twelve weeks postoperatively to evaluate bite force, occlusion, and range of mandibular movements (mouth opening, lateral excursive and protrusive movements). (Fig. 3a-c \& Fig.4a-d)

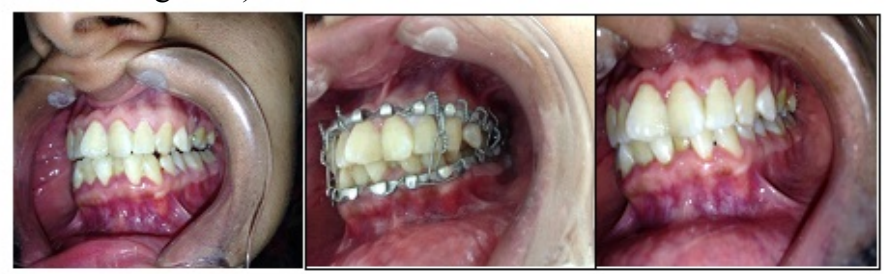

Fig. 3: Showing occlusion a) Preoperative occlusion, b) Two weeks postoperative occlusion, c) Six \& twelve weeks postoperative occlusion.

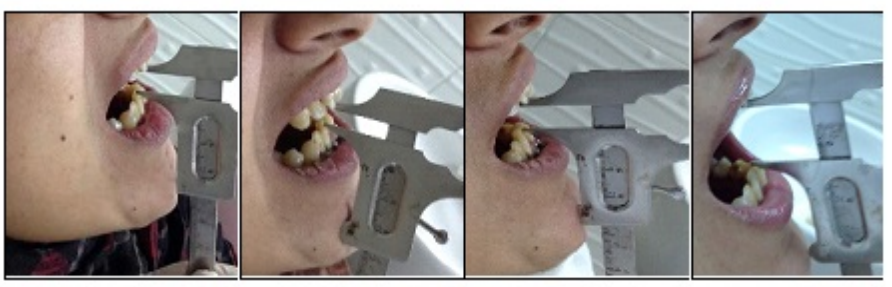

Fig. 4: Showing mouth opening a) Preoperative mouth opening, b) Two weeks postoperative mouth opening following removal of MMF, c) Two weeks postoperative mouth opening following application of arthrocentesis, d) Six and twelve weeks postoperative mouth opening.

Regarding the maximum mouth opening, a limited mouth opening was obvious preoperatively but the mouth opening improved gradually postoperatively. The maximum mouth opening scores at 2 weeks, 4 weeks, 6 weeks and 12 weeks postoperatively is shown in table 1 . The maximum mouth opening (MO) was increased in all cases in both groups through-out the follow up periods where the increase in the mean of the MO scores after two, four, six and twelve weeks was found to be statistically significant in comparison to that measured preoperatively in both groups ( $\mathrm{p} 1$ value $<0.05)$. There was a significant increase in MO score in group I by the end of the second week after arthrocentesis in comparison to that just before arthrocentesis in the same week as p2 $=0.001(\mathrm{P} 2<0.05)$.

There was no statistical significance difference in $\mathrm{MO}$ scores between group I and II in the first two weeks (before arthrocentesis was done in cases of group I) as $p$ value $>$ 0.05. After arthrocentesis was done in group I, there was a significance difference in MO scores between group I and II by the end of the second, fourth, sixth and twelfth week ( $p$ value $<0.05$ ).

The lateral excursive movements either towards the affected side or non-affected side in were measured in group 
I \& II. They were increased in all cases in

both groups through-out the follow up periods, this increase in the mean of these scores after two, four, six and twelve weeks was found to be statistically significant in comparison to that measured preoperatively in both groups ( $\mathrm{p} 1$ value $<0.05)$. There was a significant increase in these score in group I by the end of the second week after arthrocentesis in comparison to that just before arthrocentesis in the same week as p2 $=0.001(\mathrm{P} 2<0.05)$

Table 1: Showing the maximum mouth opening scores at 2 weeks, 4 weeks, 6 weeks and 12 weeks postoperatively.

\begin{tabular}{|c|c|c|c|c|c|c|}
\hline \multirow{2}{*}{$\begin{array}{l}\text { Mouth } \\
\text { pening }\end{array}$} & \multicolumn{6}{|c|}{ Week } \\
\hline & Preoperative & $2^{\text {nd }}$ Before & $\mathbf{2}^{\text {nd }}$ After & $4^{\text {th }}$ & $6^{\text {th }}$ & $12^{\text {th }}$ \\
\hline \multicolumn{7}{|l|}{ Group I } \\
\hline Min. - Max. & $10.10-19.0$ & $10.0-18.0$ & $16.0-26.0$ & $20.0-34.0$ & $24.0-37.0$ & $30.0-40.0$ \\
\hline Mean \pm SD. & $14.91 \pm 3.52$ & $13.95 \pm 3.32$ & $20.30 \pm 3.89$ & $27.0 \pm 4.56$ & $30.50 \pm 4.14$ & $\begin{array}{c}33.80 \pm \\
3.85\end{array}$ \\
\hline Median & 16.0 & 14.25 & 19.50 & 28.0 & 31.50 & 33.50 \\
\hline $\mathbf{p}_{1}$ & & $0.001^{*}$ & $<0.001^{*}$ & $<0.001^{*}$ & $<0.001^{*}$ & $<0.001^{*}$ \\
\hline $\mathbf{p}_{2}$ & & \multicolumn{2}{|c|}{$<0.001^{*}$} & & & \\
\hline \multicolumn{7}{|l|}{ Group II } \\
\hline $\begin{array}{l}\text { Min. - } \\
\text { Max. }\end{array}$ & $10.0-19.0$ & \multicolumn{2}{|c|}{$9.0-18.0$} & $14.0-22.0$ & $20.0-25.0$ & $25.0-30.0$ \\
\hline $\begin{array}{l}\text { Mean } \\
\pm \text { SD. }\end{array}$ & $15.10 \pm 3.1$ & \multicolumn{2}{|c|}{$13.70 \pm 2.95$} & $17.90 \pm 2.56$ & $23.0 \pm 2.0$ & $\begin{array}{c}28.50 \pm \\
1.78\end{array}$ \\
\hline $\begin{array}{l}\text { Media } \\
\mathrm{n}\end{array}$ & 16.0 & \multicolumn{2}{|c|}{14.50} & 18.0 & 23.0 & 29.0 \\
\hline $\mathbf{p}_{1}$ & & \multicolumn{2}{|c|}{$<0.001^{*}$} & $<0.001^{*}$ & $<0.001^{*}$ & $<0.001^{*}$ \\
\hline $\mathbf{T}$ & 0.128 & 0.178 & $4.278^{*}$ & $5.500^{*}$ & $5.155^{*}$ & $3.949^{*}$ \\
\hline $\mathbf{P}$ & 0.900 & 0.861 & $<0.001^{*}$ & $<0.001^{*}$ & $<0.001^{*}$ & $0.001^{*}$ \\
\hline
\end{tabular}

p1: Stands for adjusted Bonferroni p-value for ANOVA with repeated measures for comparison between 1st week with each other period

p2: $\mathrm{p}$ value for Paired t-test for comparing between 2nd week before and after

$\mathrm{t}$ : Student t-test

$*$ : Statistically significant at $\mathrm{p} \leq 0.05$

There was no statistical significant difference in scores between group I and II in the first two weeks (before arthrocentesis was done in cases of group I) as p value > 0.05. After arthrocentesis was done in group I, there was a significance difference in these scores between group I and II by the end of the second and fourth week ( $p$ value $<0.05$ ), but became nearly the same by the end of sixth and twelfth week in both group I and II. (Table 2)

The protrusive movements were measured in group I \& II. They were increased in all cases in both groups throughout the follow up periods, this increase in the mean of these scores after two, four, six and twelve weeks was found to be statistically significant in comparison to that measured preoperatively in both groups ( $\mathrm{p} 1$ value $<0.05$ ). There was a significant increase in these score in group I by the end of the second week after arthrocentesis in comparison to that just before arthrocentesis in the same week as p2 $=0.001$ $(\mathrm{p} 2<0.05)$

Table 2: Showing comparison between the two studied groups according to lateral excursive movement.

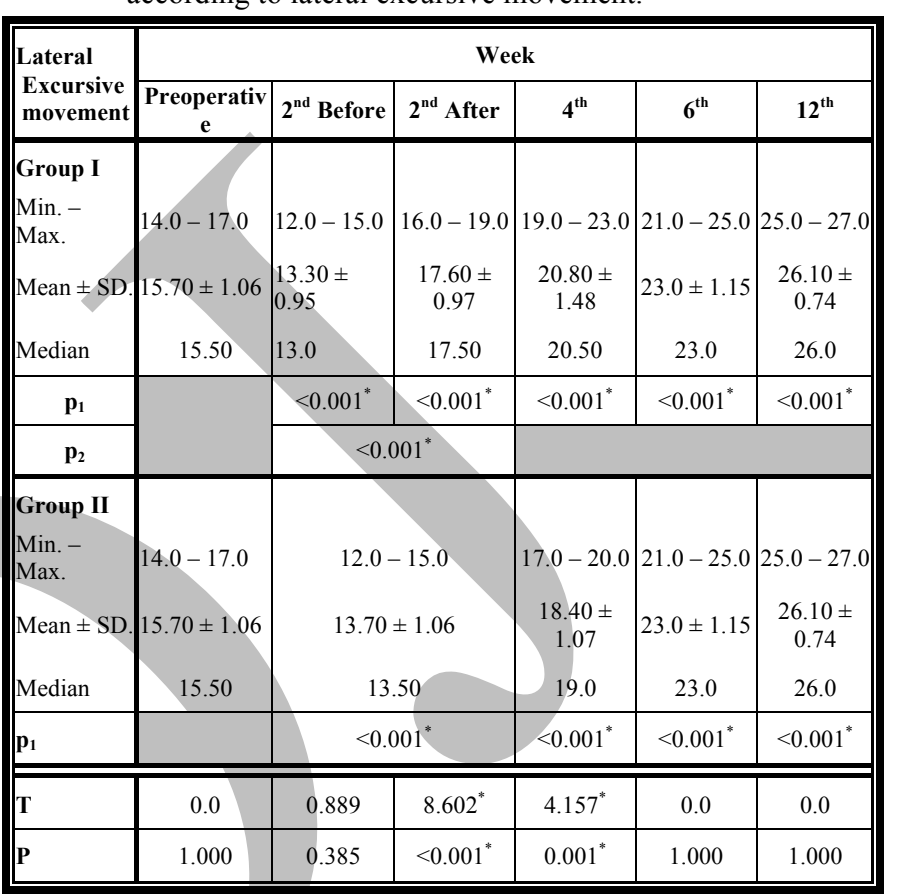

p1: Stands for adjusted Bonferroni p-value for ANOVA with repeated measures for comparison between 1st week with each other period

p2: $p$ value for Paired t-test for comparing between 2 nd week before and after

t: Student t-test

*: Statistically significant at $\mathrm{p} \leq 0.05$

There was no statistical significance difference in scores between group I and II in the first two weeks (before arthrocentesis was done in cases of group I) as p value > 0.05. After arthrocentesis was done in group I, there was a significance difference in these scores between group I and II by the end of the second and fourth week ( $\mathrm{p}$ value $<0.05$ ), but became nearly the same by the end of sixth and twelfth week in both group I and II. (Table 3)

The percentage of change in the bite force was measured in group I \& II. It was increased in all cases in both groups through-out the follow up periods, this increase in the mean of these scores after two, four, six and twelve weeks was found to be statistically significant in comparison to that measured preoperatively in both groups ( $\mathrm{p} 1$ value $<0.05$ ). There was a significant increase in these score in group I by the end of the second week after arthrocentesis in comparison to that just before arthrocentesis in the same week as $\mathrm{p} 2=0.001(\mathrm{p} 2<0.05)$

There was no statistical significance difference in scores 
between group I and II in the first two weeks (before arthrocentesis was done in cases of group I) as $p$ value $>$ 0.05. After arthrocentesis was done in group $I$, there was a significance difference in these scores between group I and II by the end of the second and fourth week ( $p$ value $<0.05$ ), but became nearly the same by the end of sixth and twelveth week in both group I and II.( Fig. 5)

Concerning wound healing and sensory function in cases of ORIF, no infection or wound dehiscence were detected nor impairment in the normal sensation.

Table 3: Showing comparison between the two studied groups according to protrusive movement.

\begin{tabular}{|c|c|c|c|c|c|c|}
\hline \multirow{2}{*}{$\begin{array}{l}\text { Protrusive } \\
\text { movement }\end{array}$} & \multicolumn{6}{|c|}{ Week } \\
\hline & Preoperative & $2^{\text {nd }}$ Before & $2^{\text {nd }}$ After & $4^{\text {th }}$ & $6^{\text {th }}$ & $12^{\text {th }}$ \\
\hline \multicolumn{7}{|l|}{ Group I } \\
\hline Min. - Max. & $2.0-5.0$ & $1.0-4.0$ & $3.0-6.0$ & $5.0-7.0$ & $4.0-6.0$ & $4.0-6.0$ \\
\hline Mean \pm SD & $3.40 \pm 0.97$ & $2.40 \pm 0.97$ & $4.40 \pm 0.84$ & $6.20 \pm 0.79$ & $4.90 \pm 0.74$ & $5.30 \pm 0.82$ \\
\hline Median & 3.0 & 2.0 & 4.0 & 6.0 & 5.0 & 5.50 \\
\hline $\mathbf{p}_{1}$ & & $<0.001^{*}$ & $<0.001^{*}$ & $<0.001^{*}$ & $<0.001^{*}$ & $<0.001^{*}$ \\
\hline $\mathbf{p}_{2}$ & & \multicolumn{2}{|c|}{$0.003^{*}$} & & & \\
\hline Group II & & \multirow{2}{*}{\multicolumn{2}{|c|}{$1.0-3.0$}} & & & \\
\hline Min. - Max. & $2.0-5.0$ & & & $4.0-6.0$ & $4.0-6.0$ & $4.0-6.0$ \\
\hline Mean \pm SD & $3.30 \pm 1.06$ & \multicolumn{2}{|c|}{$2.10 \pm 0.57$} & $4.70 \pm 0.82$ & $5.0 \pm 0.82$ & $5.30 \pm 0.82$ \\
\hline Median & 3.0 & \multicolumn{2}{|c|}{2.0} & 4.50 & 5.0 & 5.50 \\
\hline $\mathbf{p}_{1}$ & & \multicolumn{2}{|c|}{$0.001^{*}$} & $0.001^{*}$ & $<0.001^{*}$ & $<0.001^{*}$ \\
\hline $\mathbf{T}$ & 0.221 & 0.847 & $7.155^{*}$ & $4.160^{*}$ & 0.287 & 0.0 \\
\hline $\mathbf{P}$ & 0.828 & 0.408 & $<0.001^{*}$ & $0.001^{*}$ & 0.777 & 1.000 \\
\hline
\end{tabular}

p1: Stands for adjusted Bonferroni p-value for ANOVA with repeated measures for comparison between 1 st week with each other period

p2: $\mathrm{p}$ value for Paired t-test for comparing between 2nd week before and after

t: Student t-test

*: Statistically significant at $\mathrm{p} \leq 0.05$

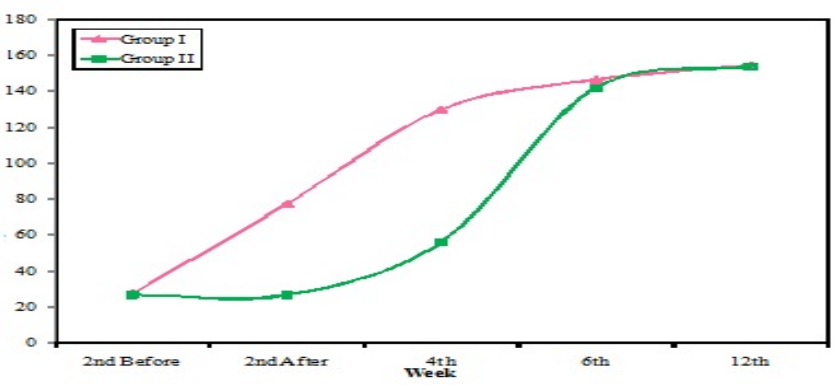

Fig. 5: Line graph showing comparison between the two studied groups according to the percentage of change in the bite force.

\section{Radiographic results:}

Immediate postoperative panoramic X-ray, showed satisfactory reduction in all cases having contralateral parasymphyseal or body fracture with proper bony alignment at the lower border of the mandible and proper occlusion. Radiographic follow up was continued at the intervals of four, sixth and twelve weeks postoperative which showed progressive improvement in bone healing and stability of the fracture segments. (Fig. 6a-c)
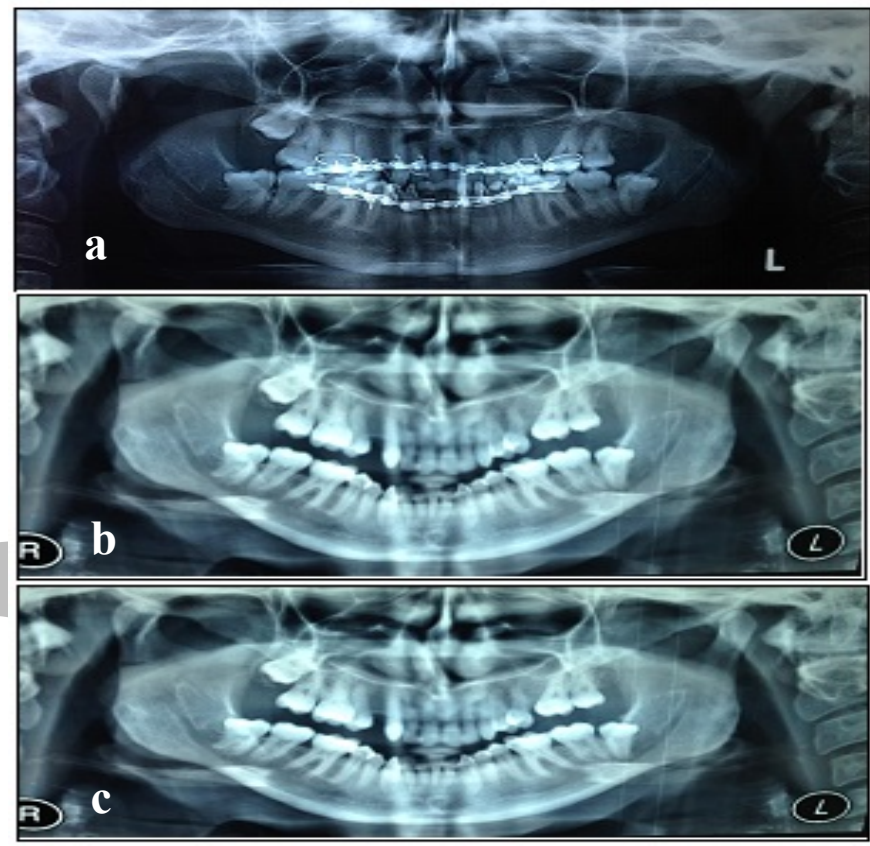

Fig. 6: a) Immediate postoperative OPG view, b) Six weeks postoperative $\mathrm{OPG}, \mathrm{c}$ ) Twelve weeks postoperative OPG.

\section{DISCUSSION}

This study was performed to detect whether arthrocentesis can overcome the disadvantages of MMF and restore the normal mouth opening or not. In the current study, the period of maxillomandibular fixation did not exceed 14 days in all cases of both the study and the control group. This is advised to avoid any negative musculoskeletal changes or decrease in the range of mandibular opening that may occur if maxillomandibular fixation (MMF) was left long (9-11).

The age distribution involved in this study ranged from $20-50$ with a mean age of 27 years which is consistent with previously published reviews $(14,21-26)$. This could be related to the fact that young adults represent a wide section of the population and are involved in violence and take part in dangerous exercises or sports (11).

In this study, the females showed a higher prevalence than male with a ratio $2: 1$ unlike a retrospective study made on the medical records and radiographs of 509 patients treated for mandibular fracture at the University of Alexandria Hospital between 1991 and 2000 (11), where the male to female ratio was 3.6:1.

Regarding the etiology of fracture, this study showed that traffic accidents, falls and assaults are the main causes of fracture representing $45 \%, 30 \%$ and $25 \%$ respectively with the primary cause being the traffic accidents in males and assaults or falls in females. This is consistent with a retrospective study done to show that among male patients 
road traffic crashes accounted for the highest percentage $(42 \%)$ followed by falls $(32 \%)$, assaults $(18 \%)$, and sports injuries $(6 \%)$ while among female patients the highest percentage $(51 \%)$ were caused by falls followed by crashes (36\%), assaults (9\%) and sports (4\%) (27). This may be due to the availability of car and motor vehicles to young people, insufficient stress on the use of seat belts, high-speed driving, and less enforcement of traffic rules and regulations in the Middle East $(22,25)$.

Regarding the site of fracture, this study involved 10 cases showing isolated subcondylar fractures and 10 cases with contralateral parasymphyseal or mandibular body fracture in addition. The site of fracture is affected by the type, magnitude and direction of traumatic force $(25,26)$. This is also proven through a 5 year study made in 2003 and showed that $32 \%$ of fractures are seen in the condylar region; $29.3 \%$ in the symphyseal-parasymphyseal region, $20 \%$ in the angle region, $12.5 \%$ in the body, $3.1 \%$ in the ramus, $1.9 \%$ in the dentoalveolar, and $1.2 \%$ in the coronoid region (9).

In the current study, there was a significant increase in the percentage of bite forces in both study and control group across the follow up period with a significant difference in the study group in relation to the control one especially in the second and fourth week due to the application of arthrocentesis. This is in agreement with the study in 2004 which proved that arthrocentesis (TMJ lavage) was found to be effective for washing out bradykinin, interleukin-6, and protein from TMJ (14) this helped to bite normally because the pain mediators are removed.

Concerning the range of mouth opening, lateral excursive and protrusive movements, there was a significant improvement within each group through-out the follow up periods. Regarding the lateral excursive and protrusive movements the study showed obvious significant difference between the two groups especially at the second week following the application of arthrocentesis and this improvement continued through-out the fourth week but with no significant difference in sixth and twelfth week. However, the range of mouth opening continued to show remarkable significant difference between the two groups up to the twelfth week postoperatively. This is consistent in part with a study made to clinically compare between arthrocentesis and conventional conservative treatment in 2014 and proved that there were no significant differences in protrusive, lateral excursive movement or incidence of malocclusion but the mandibular range of motion and joint pain showed good improvement from the early stages of treatment and showed better outcomes (28). The significant improvement in the mandibular movements in study group immediately after the application of arthrocentesis showed that arthrocentesis has a great impact on restoring the normal mouth opening and improving the quality of life in patients (12).

In cases with contralateral parasymphyseal or mandibular body fracture and who were treated by ORIF, small incision and gentle soft tissue dissection for the placement of the conventional miniplates which decreased the risk of infection and soft tissue dehiscence This was in agreement with the study made in 2013 showing that one of the advantages of conventional miniplate is low rate of infection (29).

\section{CONCLUSIONS}

From the results of this study it was concluded that Arthrocentesis (TMJ lavage) is an effective procedure for washing out inflammatory mediators present within the TMJ following the exposure to trauma. Such lavage had a significant improvement of quality of life of patients and showed immediate significant difference on the spot of performing the arthrocentesis in increasing the mouth opening, lateral excursive and protrusive movements in addition to the bite force and caused significant decrease in the intensity of pain. These changes are valuable to the patients exposed to trauma where they became able to practice their usual activities and return back to normal life starting from the second week postoperatively i.e patients rehabilitation occurred in a short period.

\section{CONFLICT OF INTEREST}

The authors declare that they have no conflicts of interest.

\section{REFERENCES}

1. Ogundare BO, Bonnick A, Bayley N. Pattern of mandibular fractures in an urban major trauma center. $\mathrm{J}$ Oral Maxillofac Surg 2003; 61: 713-8.

2. Thaller SR. Management of mandibular fractures. Arch Otolaryngol Head Neck Surg 1994; 120: 44-7.

3. Zachariades N, Mezitis M, Mourouzis C, Papadakis D, Spa-nou A. Fractures of the mandibular condyle: a review of 466 cases. Literature review, reflections on treatment and proposals. J Craniomaxillofac Surg 2006; 34: 421-32.

4. Ward BB, Edward SP, Feinberg SE. Healing of Traumatic Injury. In: Fonseca, Walker, Betts, Barber, Powers. Oral and Maxillofacial Trauma. 3rd edition, Ch 19, Elsevier Saunders, USA 2005; 523-68.

5. Guillermo EC, Larsen PE. Principles of Management of Mandibular Fractures. In: Miloro M, Ghali GE, Larsen PE, Waite PD. Peterson's Principles of Oral and Maxillofacial Surgery. 2nd ed, Ch 22, BC Decker Inc, London 2004; 401-33.

6. Nogami S, Yamauchi K, Kataoka Y, Takano H, Yamashita Y, Takahashi T. Clinical comparison between arthrocentesis and conventional conservative treatment with maxillomandibular fixation for unilateral high condylar fractures. J Oral Rehabilitation 2013; 41: 141-7.

7. Suzuki T, Kawamura $H$, Kasahara T, Nagasaka $H$. Resorbable poly-L-lactide plates and screws for the treatment of mandibular condylar process fractures: a clinical and radiologic analysis. J Oral Maxillofac Surg 2004; 62: 919-24.

8. Ward BB, Edward SP, Feinberg SE. Healing of Traumatic Injury. In: Fonseca, Walker, Betts, Barber, Powers. Oral and Maxillofacial Trauma. 3rd edition, Ch 
39, Elsevier Saunders, USA 2005; 1130-70.

9. Jokl P, Konstadt S. The effect of limb immobilization on muscle function and protein composition. Clin Orthop Relat Res 1983; 174: 222-9.

10. Ellis E, Dechow PC, Carlson DS. A comparison of stimulated bite force after mandibular advancement using rigid and nonrigid fixation. J Oral Maxillofac Surg 1988; 46: 26-32.

11. Ellis E. Mobility of the mandible following advancement using maxillomandibular fixation and rigid internal fixation-an experimental investigation in Macaca mulatta. J Oral Maxillofac Surg 1988; 46: 11823.

12. Dooley P, Martic R. Corticosteroid injection and arthrocentesis. Canadian Family of Physicians 2002; 48: 285-92.

13. Nogami S, Takahashi T, Ariyoshi W, Yoshiga D, Morimoto Y, Yamauchi K. Increased levels of interleukin- 6 in synovial lavage fluid from patients with mandibular condyle fractures: correlation with magnetic resonance evidence of joint effusion. J Oral Maxillofac Surg 2013; 71: 1050-8.

14. Kaneyama K, Segami N, Nishimura M, Sato J, Fujimura K, Yoshimura H. The Ideal lavage volume of Bradykinin, Interleukin 6 and protein from the temporomandibular Joint by arthrocentesis. Journal of oral and Maxillofacial Surgery 2004; 62: 657-61.

15. Bamgbose B, Akinwande J, Adeyemo W, Ladeinde A, Arotiba G, Ogunlene M. Effects of co-administered dexamethasone \& diclofenac potassium on pain, swelling \& trismus following third molar surgery. Head $\&$ Face Medicine 2005; 1: 11-6.

16. Gert S, Hans K, Josef S. MRI imaging of the TMJ: MR diagnosis and intraoperative findings. Journal of Cranio Maxillofacial Surgery 1993; 21: 284-8.

17. Emshoff R, Gerhard S, Ennemoser T, Rudisch A. Magnetic resonance imaging findings of internal derangement, osteoartrosis, effusion and bone marrow edema before and after performance of arthrocentesis and hydraulic distension of the temporomandibular joint. Oral Surg Oral Med Oral Pathol Oral Radiol Endod 2006; 101: 784-90.

18. William C, Marianne P, Lewis R. A modified auriculotemporal nerve block for regional anesthesia of the temporomandibular joint. J Oral Maxillofac Surg 1984; 42: 544-5.

19. Kotz S, Balakrishnan N, Read CB, Vidakovic B. Encyclopedia of statistical sciences. 2nd ed. Hoboken, N.J.: Wiley-Interscience; 2006.

20. Kirkpatrick LA, Feeney BC. A simple guide to IBM SPSS statistics for version 20.0. Student ed. Belmont, Calif.: Wadsworth, Cengage Learning; 2013.

21. Bataineh AB. Etiology and incidence of maxillofacial fractures in the north of Jordan. Oral Surg Oral Med Oral Pathol 1998;86:31-5.

22. Adi M, Ogden GR, Chisholm DM. An analysis of mandibular fractures in Dundee, Scotland (1977 to 1985). Br J Oral Maxillofac Surg 1990;28:194-9.
23. Marke P, Nielsen A, Basian HL. Fractures of the mandibular condyle. Part 2: results of treatment of 348 patients.Br J Oral Maxillofac Surg 2000;385:422-6.

24. Marke P, Nielsen A, Basian HL. Fractures of the mandibular condyle.Part 1: Patterns of distribution of types and causes of fractures in 348 patients. $\mathrm{Br} \mathrm{J}$ Maxillofac Surg 2000;38;417-21.

25. Khalil AF, Shaladi OA. Fractures of the facial bones in the Eastern region of Libya. Br J Oral Surg 1981;19:300-4.

26. Van Hoof RF, Merkx CA, Stekelenburg EC. The different patterns of fractures of the facial skeleton in four European countries. Int J OralSurg 1993;6:3-11.

27. Sakr k, Farag I, Zeitoun I. Review of 509 mandibular fractures treated at the university hospital, Alexandria, Egypt. Br J Oral Maxillofac Surg 2006; 44: 107-11.

28. Nogami S, Yamauchi K, Kataoka Y, Takano H, Yamashita Y, Takahashi T. Clinical comparison between arthrocentesis and conventional conservative treatment with maxillomandibular fixation for unilateral high condylar fractures. J Oral Rehabilitation 2014; 41: 141-7.

29. Sadhwani B, Anchlia S. Conventional $2.0 \mathrm{~mm}$ miniplates versus 3-D plates in mandibular fractures. Ann Maxillofac Surg 2013; 3: 154-9. 